Supporting Information for:

\title{
Ammonia Capture via an Unconventional Reversible Guest-Induced Metal-Linker Bond Dynamics in a Highly Stable Metal-Organic Framework
}

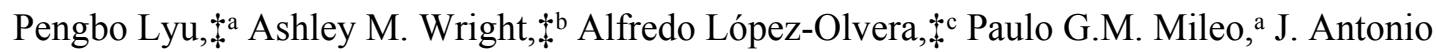
Zárate, ${ }^{\mathrm{a}, \mathrm{c}}$ Eva Martínez-Ahumada, ${ }^{\mathrm{c}}$ Vladimir Martis, ${ }^{\mathrm{d}}$ Daryl R. Williams, ${ }^{\mathrm{e}, \mathrm{f}}$ Mircea Dincă,${ }^{* b}$ Ilich A. Ibarra, ${ }^{* c}$ and Guillaume Maurin ${ }^{* a}$

anstitut Charles Gerhardt Montpellier, UMR-5253, Université de Montpellier, CNRS, ENSCM, Place E. Bataillon, 34095 Montpellier cedex 05, France. E-mail: guillaume.maurin1@umontpellier.fr.

bepartment of Chemistry, Massachusetts Institute of Technology, 77 Massachusetts Avenue, Cambridge, Massachusetts 02139, United States. E-mail: mdinca@mit.edu.

${ }^{c}$ Laboratorio de Fisicoquímica y Reactividad de Superficies (LaFReS), Instituto de Investigaciones en Materiales, Universidad Nacional Autónoma de México, Circuito Exterior s/n, CU, Coyoacán, 04510, Ciudad de México, México. E-mail: argel@unam.mx; Fax: +52(55)5622-4595

d Surface Measurement Systems, Unit 5, Wharfside, Rosemont Road, London HA04PE, UK.

eSurfaces and Particle Engineering Laboratory (SPEL), Department of Chemical Engineering, Imperial College London, South Kensington Campus, London SW7 2AZ, UK.

fDirector of Discovery Space and Professor of Particle Science, Department of Chemical Engineering, Imperial College, Kensington, London SW7 2BY. 


\section{Table of Contents}

Ammonia capture by MOFs............................................................................................................2

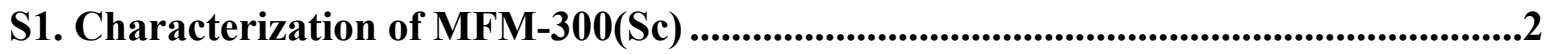

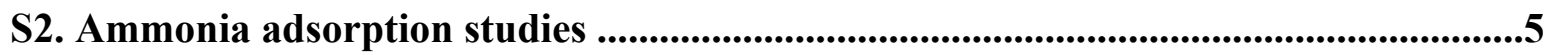

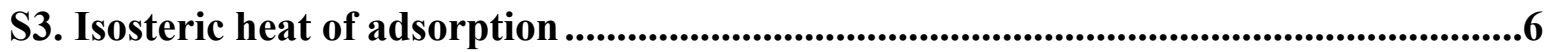

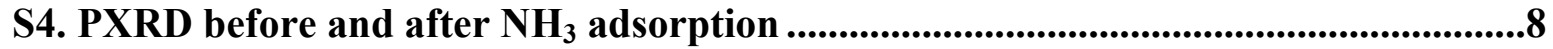

S5. Adsorption Isotherms of $\mathrm{N}_{2}$ before and after $\mathrm{NH}_{3}$ adsorption ...................................9

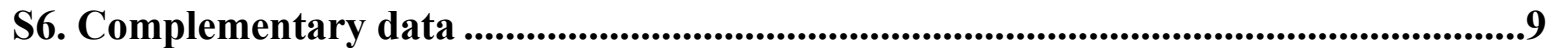

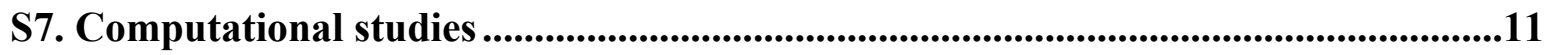

S8. DRIFT studies ....................................................................................................................16

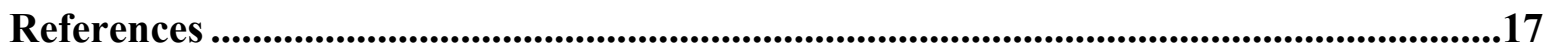

\section{Ammonia capture by MOFs}

As well known the $\mathrm{NH}_{3}$ molecule can act as Brønsted/Lewis base and hydrogen-bond donor/acceptor, two adsorption mechanisms were mostly privileged with the selection of MOFs containing either coordinatively unsaturated sites (cus) or hydroxyl-functions. In the first scenario, a series of cusMOFs, e.g., HKUST-1, ${ }^{1}$ MOF-74, ${ }^{23}$ MOF-5, ${ }^{4}$ MOF-177, ${ }^{2} \quad \mathrm{M}_{2} \mathrm{Cl}_{2} \mathrm{BTDD}(\mathrm{M}=\mathrm{Co}, \mathrm{Ni}){ }^{6}$ and $\mathrm{M}_{2} \mathrm{Cl}_{2} \mathrm{BTTA}(\mathrm{M}=\mathrm{Co}, \mathrm{Ni}, \mathrm{Cu})^{7}$ was considered too strongly bind $\mathrm{NH}_{3}$ through the formation of a Metal-N bond. Although this adsorption mode was found to ensure a highly efficient $\mathrm{NH}_{3}$ capture particularly at very low traces, unfortunately most of the time it was accompanied by a substantial loss of crystallinity or even a collapse of the MOF structures rendering the process irreversible. In the second case, high-valence metal (III) MOFs incorporating $\mu$-OH groups, e.g., $\mathrm{M}-\mathrm{PMOF}(\mathrm{M}=\mathrm{Al}, \mathrm{Ga}$, In), ${ }^{8}$ MIL-53(Al), ${ }^{9}$ and MFM-300(Al) ${ }^{10}$ were found robust enough to reversibly adsorb $\mathrm{NH}_{3}$ via $\mathrm{N}_{(\mathrm{NH} 3)^{-}}-\mathrm{H}_{(\mu-\mathrm{OH})}$ hydrogen bond-type interactions however at the expense of a lower affinity as compared to cus-MOFs.

\section{Experimental section}

S1. Characterization of MFM-300(Sc) 


\section{Crystal Structure of MFM-300(Sc)}
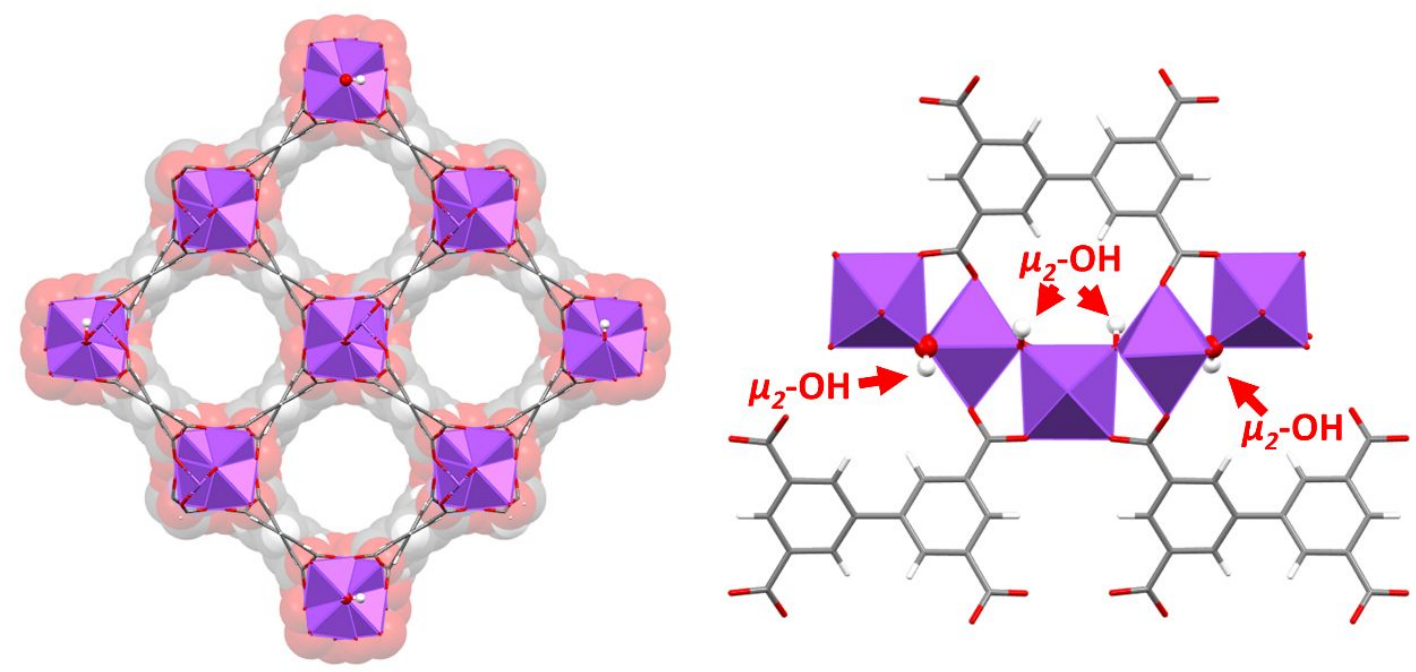

Figure S1. (left) View along the c-axis of pore channels of MFM-300(Sc). (right) view of scandium oxo-cluster in MFM-300( $\mathrm{Sc})$, showing [BPTC] ${ }^{4-}$ and $\mu_{2}-\mathrm{OH}$ group.

\section{PXRD}

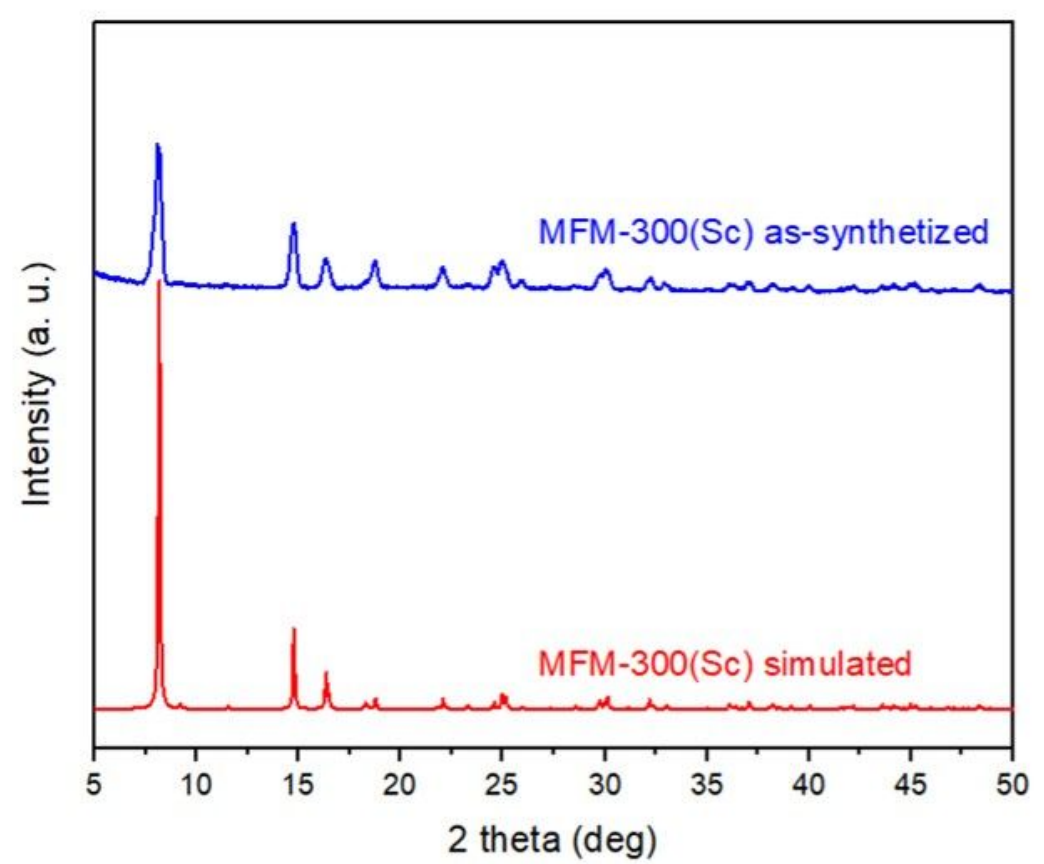

Figure S2. Experimental (blue) and simulated (red) Powder X-ray diffraction (PXRD) patterns for MFM$300(\mathrm{Sc})$.

\section{Thermogravimetric Analysis}




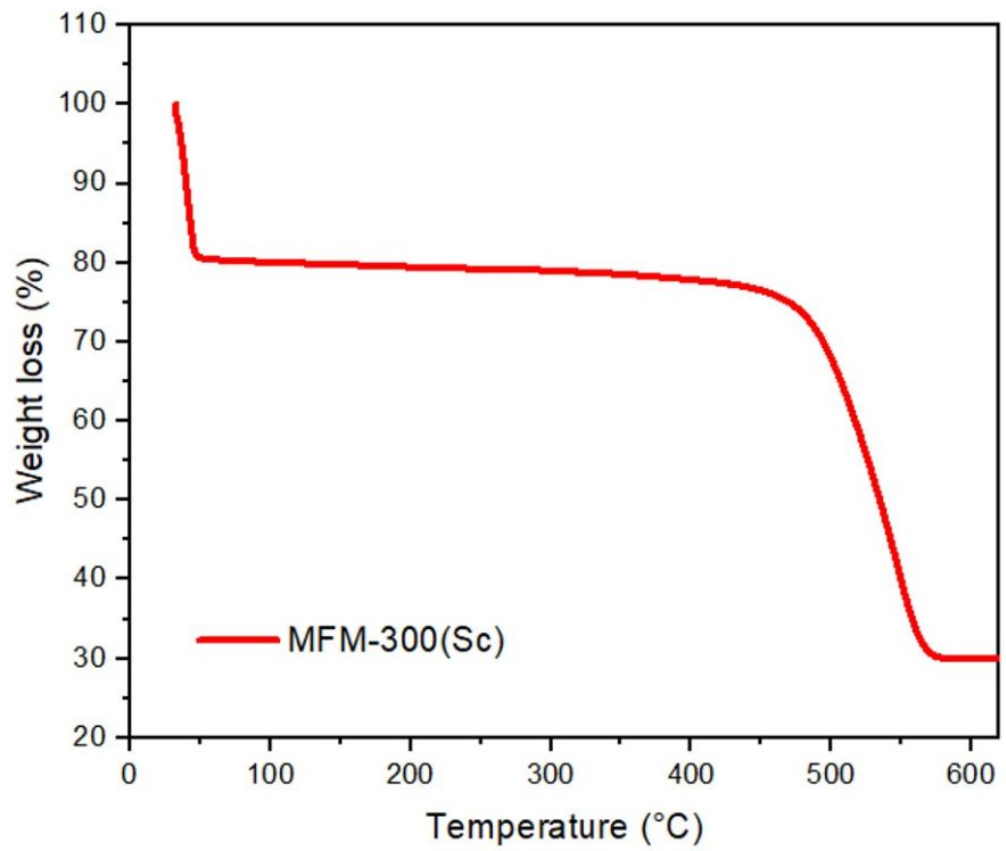

Figure S3. Thermogravimetric analysis (TGA) of the as-synthetized MFM-300(Sc) sample.

\section{Adsorption isotherm of $\mathbf{N}_{2}$}

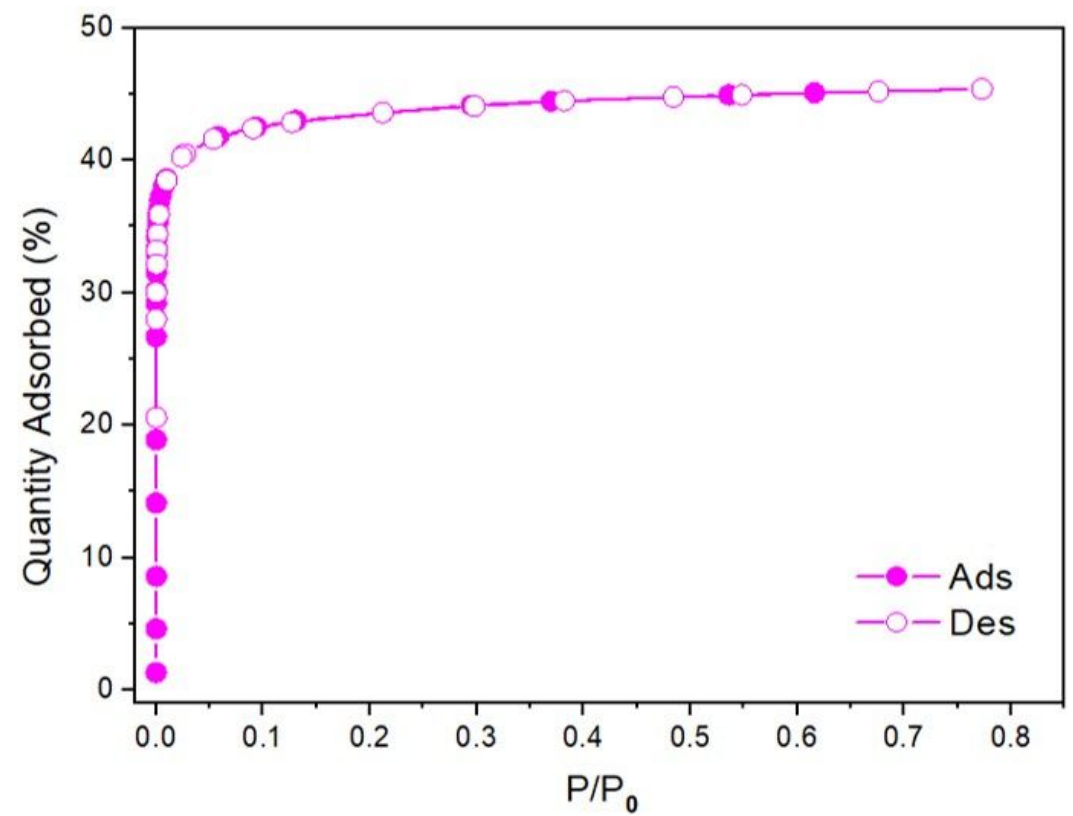

Figure S4. $\mathrm{N}_{2}$ adsorption/desorption isotherms at $77 \mathrm{~K}$ of the as synthesized MFM-300(Sc).

\section{Results and Discussion}


S2. Ammonia adsorption studies

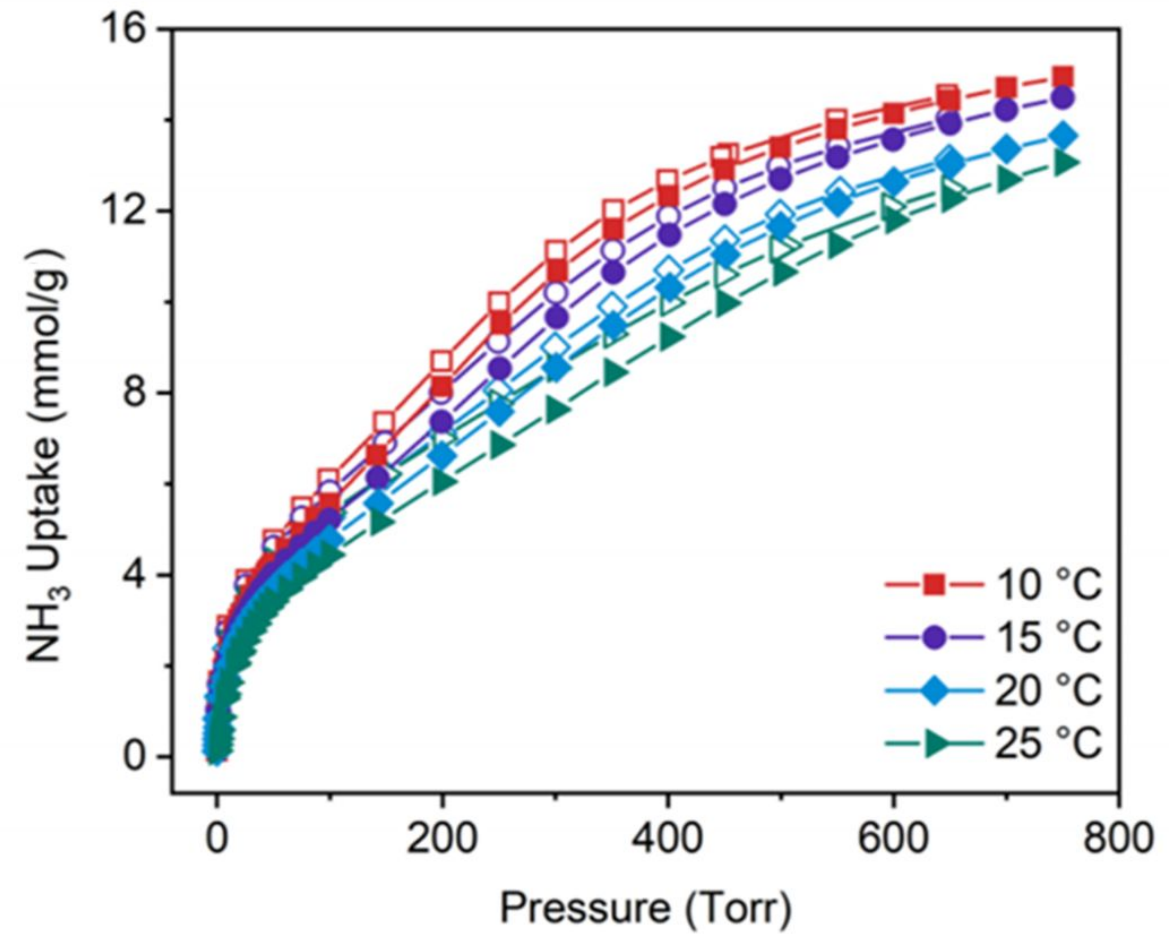

Figure S5. $\mathrm{NH}_{3}$ adsorption isotherm of MFM-300(Sc) at $298 \mathrm{~K}$. The plot shows the number of equivalents of $\mathrm{NH}_{3}$ per $\mathrm{ScOH}-\mathrm{Sc}$ unit.

Table S1. $\mathrm{NH}_{3}$ uptakes of MFM-300(Sc) at 1 bar and different temperatures.

\begin{tabular}{cc}
\hline Temperature & Uptake Capacity at 750 Torr (mmol/g STP) \\
\hline $283 \mathrm{~K}$ & 14.96 \\
$288 \mathrm{~K}$ & 14.49 \\
$293 \mathrm{~K}$ & 13.66 \\
$298 \mathrm{~K}$ & 13.07 \\
\hline
\end{tabular}




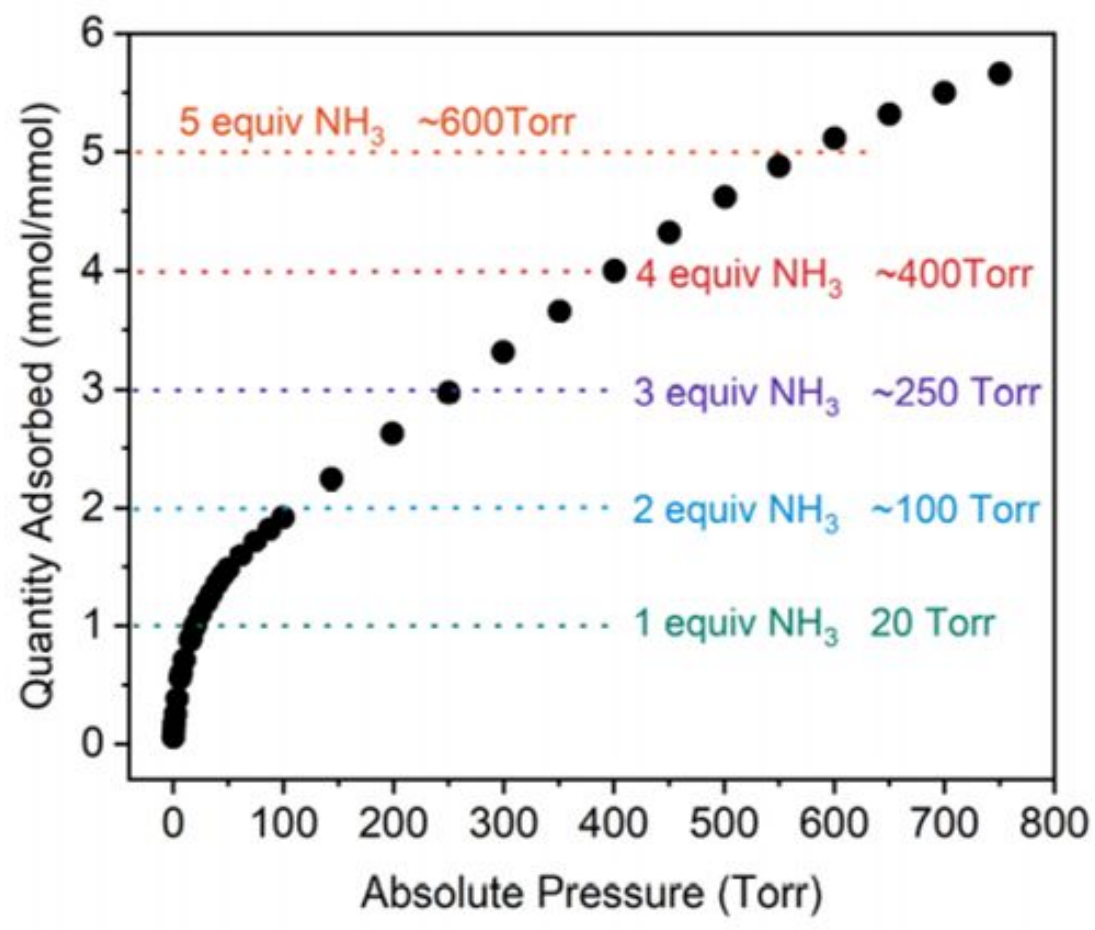

Figure S6. $\mathrm{NH}_{3}$ adsorption isotherm of MFM-300(Sc) at $298 \mathrm{~K}$. The plot shows the number of equivalents of $\mathrm{NH}_{3}$ per ScOH-Sc unit.

\section{S3. Isosteric Heat of Adsorption}

In order to determine the isosteric heat of adsorption $(Q s t)$ for $\mathrm{NH}_{3}$ binding to MFM-300(Sc), we measured isotherm data for each material at four different temperatures $(283,288,293$, and $298 \mathrm{~K})$. Initial attempts to fit the adsorption isotherm data to the Langmuir, Langmuir-Freundlich, Dual-Site Langmuir, or Dual Site Langmuir-Freundlich models resulted in a poor fit. As a result, the adsorption isotherms were simultaneously fitted to a Virial-type expression (eq. 1). The virial model has been extensively used to calculate heats of adsorption from isotherm data as the isotherms plot coverage as a function of pressure. ${ }^{12}$ Fitting with the virial-equation provided better low pressures fits.

$$
\begin{aligned}
& \operatorname{Ln} p=\operatorname{In} n+\left(\frac{1}{T}\right) \sum_{i=0}^{m} a_{i} n^{i}+\sum_{i=0}^{n} b n^{i} \\
& Q_{s t}=-R \sum_{i=0}^{m} a_{i} N^{i}
\end{aligned}
$$

The fitting parameters for the Virial equation is given in Table S3. The number of virial coefficients was considered satisfactory when the fit did not improve with added a or b parameters. The quality of the fit was evaluated by comparing adjusted $\mathrm{R}^{2}$ values and the residual sum of squares, in addition, to visually inspection of the fit. The values of the virial coefficients $a_{m}$ through am were then used to calculate the isosteric heat of adsorption using equation 2 . 
Table S2 Virial fitting parameters for the adsorption of $\mathrm{NH}_{3}$ by MFM-300(Sc).

\begin{tabular}{ccccc}
\hline index & ai & bi & Standard Error ai & Standard Error bi \\
\hline 0 & -5813.7054 & 19.58726 & 512.88447 & 1.76986 \\
1 & 512.05348 & -0.55774 & 77.55586 & 0.27242 \\
2 & -35.9019 & & 2.14742 & \\
3 & 1.24319 & & 0.10392 & \\
\hline $\mathrm{R}^{2}$ & 0.9894 & & \\
chi squared & 0.0676 & & & \\
\hline
\end{tabular}

A

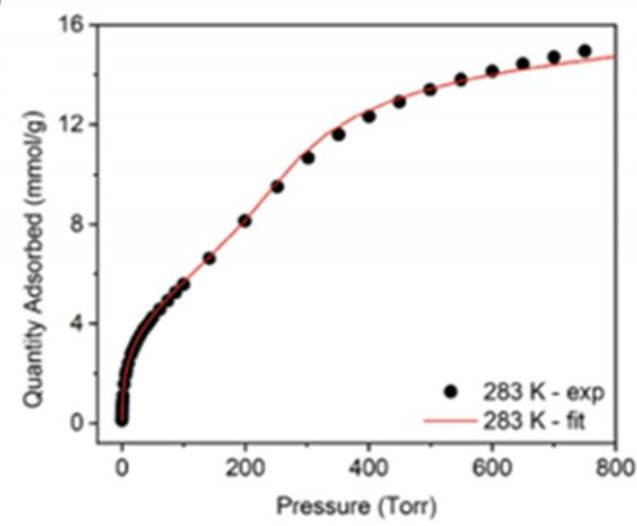

C

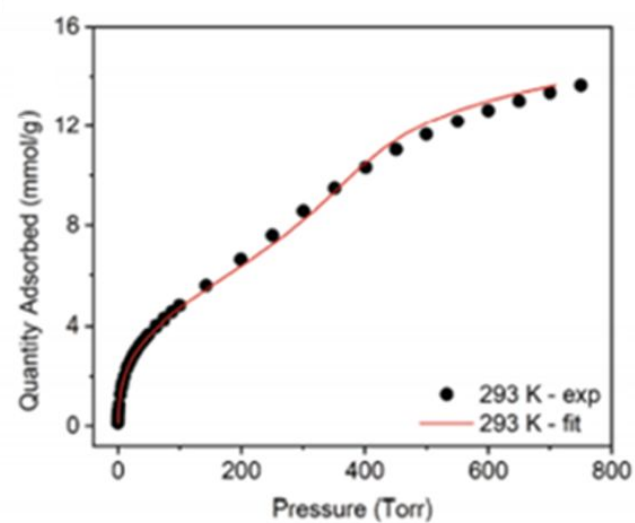

B

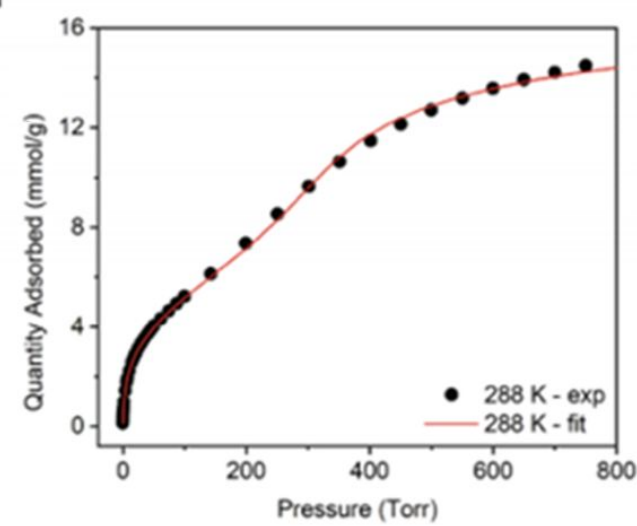

D

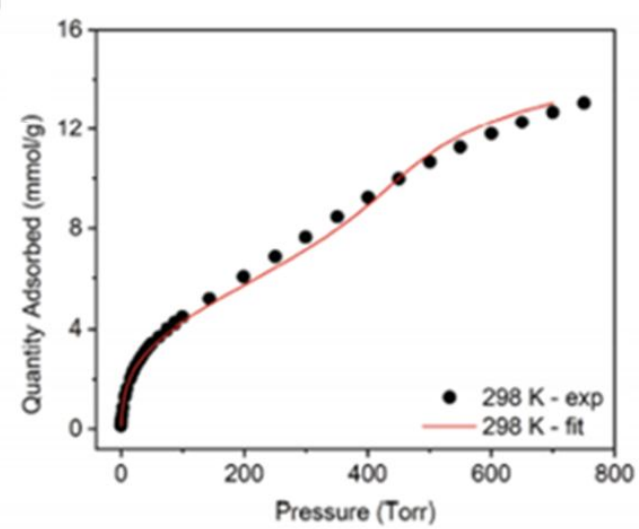

Figure S7. $\mathrm{NH}_{3}$ adsorption isotherms of MFM-300(Sc) measured at $283 \mathrm{~K}$ (plot A), $288 \mathrm{~K}$ (plot B), $293 \mathrm{~K}$ (plot C), and $298 \mathrm{~K}$ (plot D). The lines represent the Virial fitting of the adsorption isotherms. 


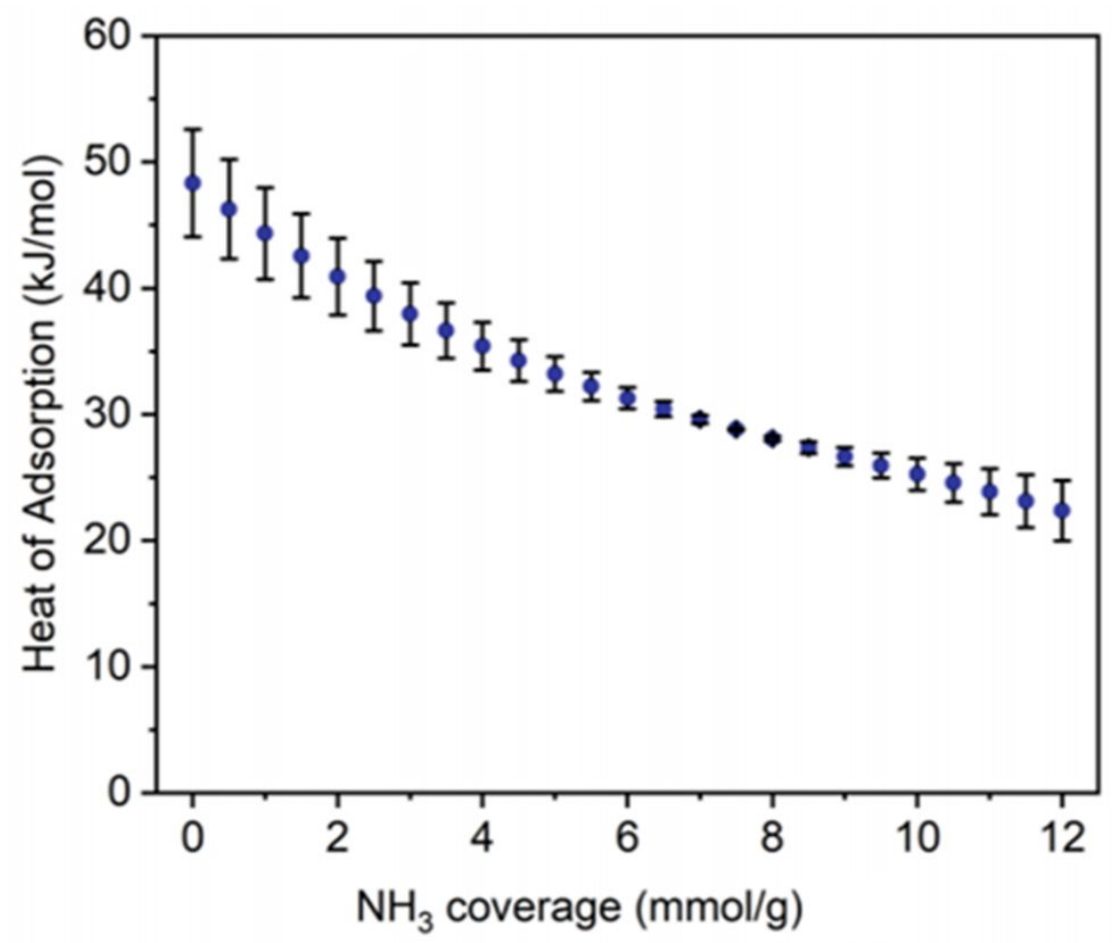

Figure S8. Coverage-dependent $\mathrm{NH}_{3}$ isosteric heat of adsorption for MFM-300(Sc) as obtained from fitting the Virial equation to four different temperature $\mathrm{NH}_{3}$ isotherms. The zero-coverage heat of adsorption is 48.3 $\mathrm{kJ} / \mathrm{mol}$.

\section{S4. PXRD before and after $\mathrm{NH}_{3}$ adsorption}

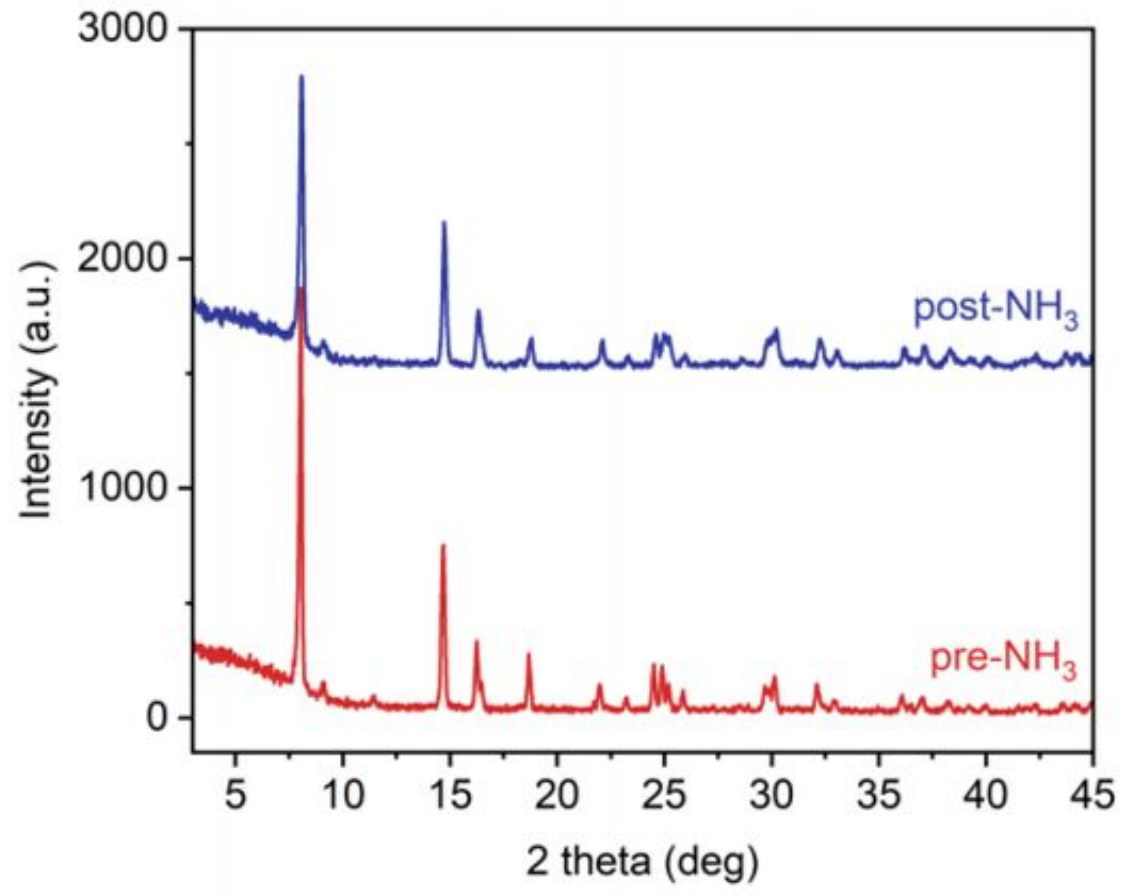

Figure S9. Powder X-ray diffraction pattern of MFM-300(Sc) before and after four $\mathrm{NH}_{3}$ isotherm cycles. 
S5. Adsorption Isotherms of $\mathrm{N}_{2}$ before and after $\mathrm{NH}_{3}$ adsorption

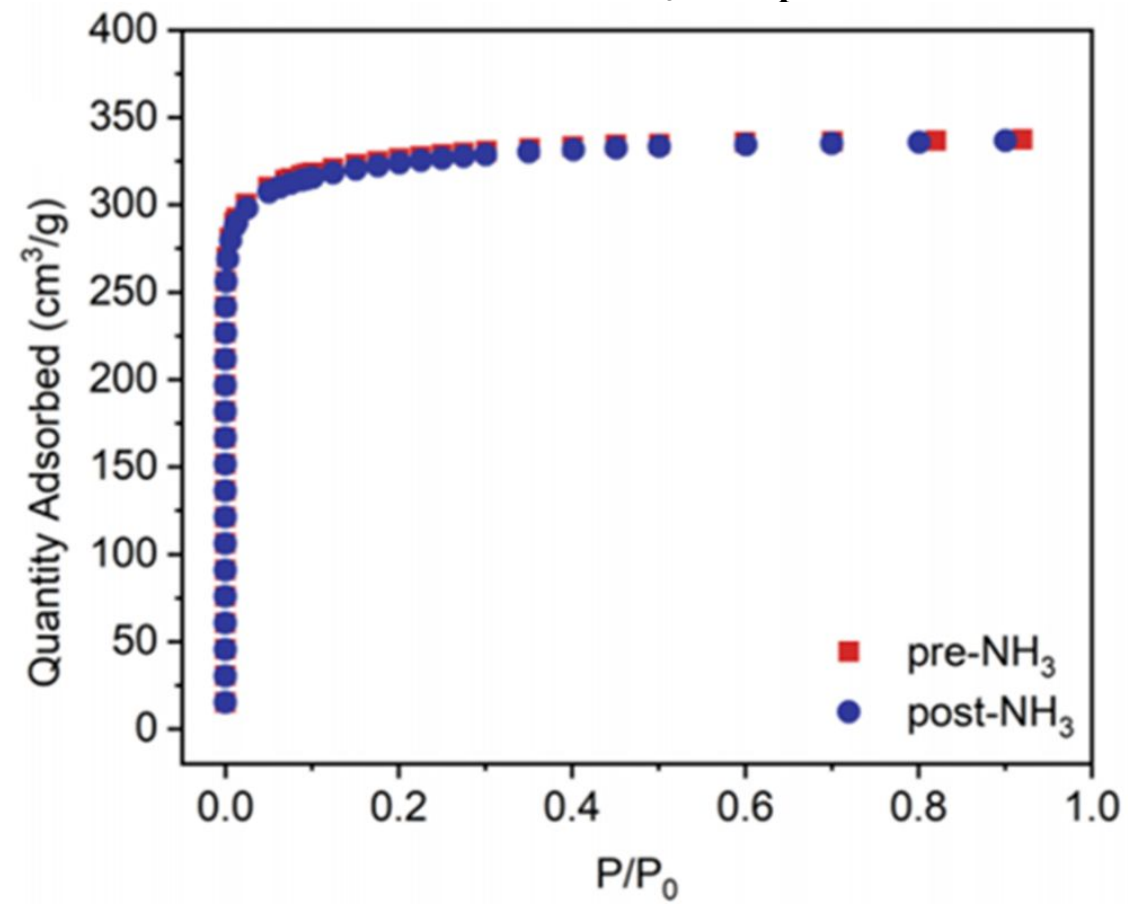

Figure $\mathbf{S 1 0} . \mathrm{N}_{2}$ isotherm of MFM-300(Sc) at $77 \mathrm{~K}$ before and after four $\mathrm{NH}_{3}$ isotherm cycles.

$\frac{\text { Table S3. BET parameters and pressure range used for the calculation of the BET area. }}{\text { Pre-NH }_{3}}$

BET surface area

$\mathbf{P} / \mathbf{P}_{\mathbf{0}}$ range

C

$\mathbf{V}_{\mathbf{m}}$

$\mathbf{P} / \mathbf{P}_{\mathbf{0}}\left(@ \mathbf{V}_{\mathrm{m}}\right)$

$1 /(\sqrt{ } \mathbf{c}+1)$
$1268 \mathrm{~m}^{2} / \mathrm{g}$

$0.000798-0.013$

5928.2

$291.4 \mathrm{~cm}^{3} / \mathrm{g} \mathrm{STP}$

0.013

0.0128
$1259 \mathrm{~m}^{2} / \mathrm{g}$

$0.00095-0.0133$

5475.5

$289.2 \mathrm{~cm}^{3} / \mathrm{g} \mathrm{STP}$

0.013

0.0133

\section{S6. Complementary data}




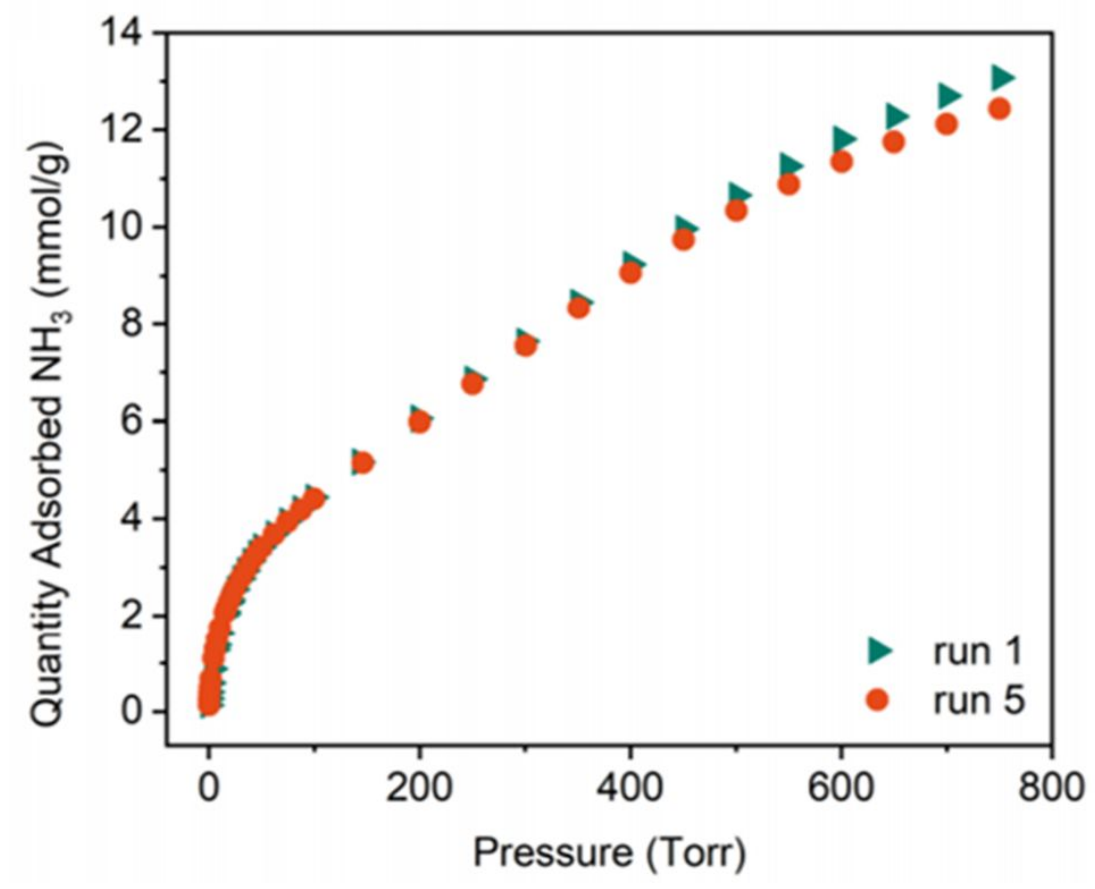

Figure S11. Comparison of $\mathrm{NH}_{3}$ isotherm of MFM-300(Sc) at $298 \mathrm{~K}$ with different equilibration times. Plot in green triangles is the first $\mathrm{NH}_{3}$ adsorption isotherm with equilibration times of 30 seconds between $0-50$ Torr and 10 seconds between 50-800 Torr. Plot in orange circles is the fifth $\mathrm{NH}_{3}$ adsorption isotherms with equilibration times of 30 seconds between $0-800$ Torr.

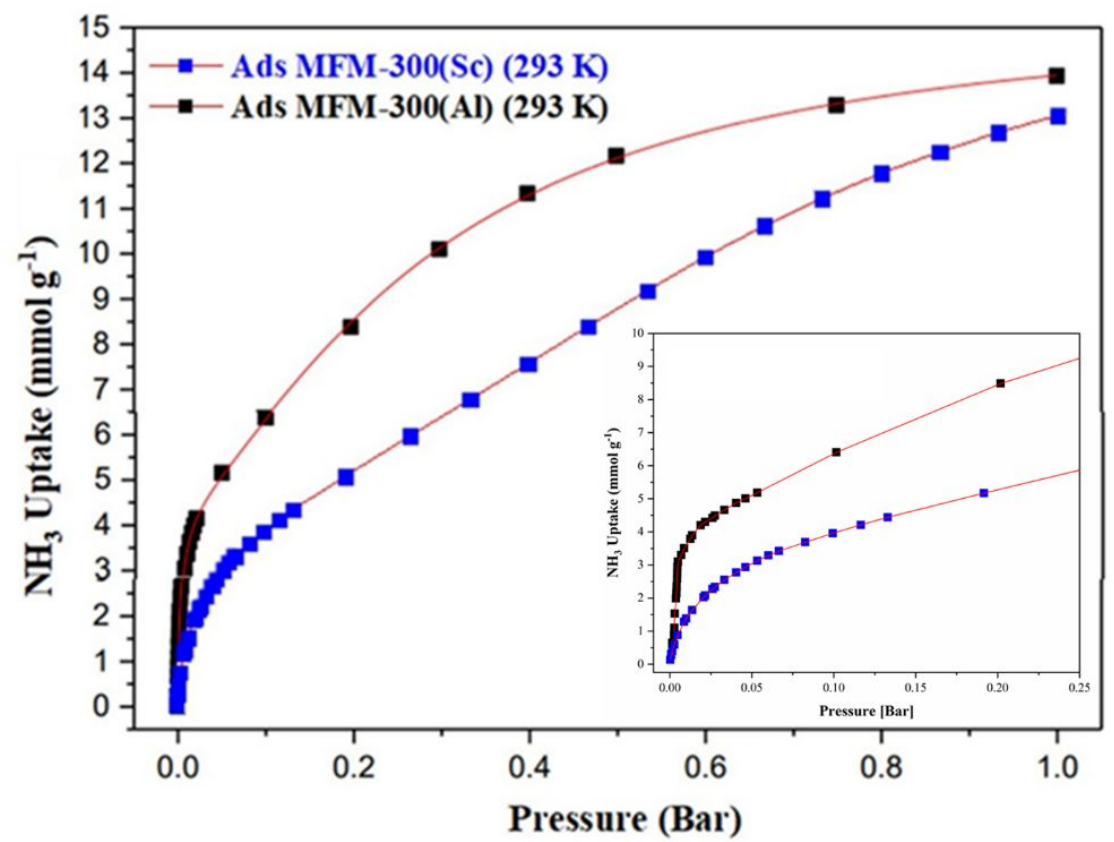

Figure S12. Comparison of $\mathrm{NH}_{3}$ Isotherms of MFM-300(Al) $)^{13}$ and MFM-300(Sc) at $293 \mathrm{~K}$ up to 1 bar. MFM$300(\mathrm{Al})$ isotherm was taken from reference [13]. Inset: comparation of $\mathrm{NH}_{3}$ isotherms of MFM-300(Al) $)^{13}$ and MFM-300(Sc) at $293 \mathrm{~K}$ up to 0.25 bar. 
Table S4. Ammonia uptakes and enthalpies for existing MOFs

\begin{tabular}{|c|c|c|c|c|}
\hline MOF & $\begin{array}{c}\mathrm{NH}_{3} \text { Uptake }\left[\mathrm{mmol} \mathrm{g}^{-1}\right] \\
\text { at } 298 \mathrm{~K} \text { and } 1 \text { bar }\end{array}$ & $\begin{array}{l}\text { Heat of adsorption } \\
{\left[\mathrm{kJ} \mathrm{mol}^{-1}\right]}\end{array}$ & $\begin{array}{c}\text { Main } \\
\text { interactions }\end{array}$ & ref \\
\hline MFM-300(Sc) & 13.07 & 48.3 & $\begin{array}{l}\text { Reversible Sc-N } \\
\text { at low pressure }\end{array}$ & $\begin{array}{l}\text { This } \\
\text { work }\end{array}$ \\
\hline $\begin{array}{c}\mathrm{M}_{2} \mathrm{Cl}_{2} \mathrm{BTDD} \\
(\mathrm{M}=\mathrm{Mn}, \mathrm{Co}, \mathrm{Ni})\end{array}$ & $15.40,12.00,12.02$ & $>85,{ }^{*}>50,{ }^{*} \sim 40^{*}$ & Open metal sites & 14 \\
\hline $\begin{array}{c}\mathrm{M}_{2}(\text { dobpdc }) \\
(\mathrm{M}=\mathrm{Mg}, \mathrm{Mn}, \mathrm{Co}, \mathrm{Ni}, \mathrm{Zn})\end{array}$ & $\begin{array}{c}29.90,13.26,13.34 \\
20.82,15.24\end{array}$ & $\begin{array}{c}159.0,{ }^{\mathrm{a}} 146.7,{ }^{\mathrm{a}} 153.8,,^{\mathrm{a}} \\
168,6^{\mathrm{a}} \\
-90.0,{ }^{\mathrm{b}}-79.4,{ }^{\mathrm{b}}-83.8,{ }^{\mathrm{b}} \\
-93.0,{ }^{\mathrm{b}}-66.6^{\mathrm{b}}\end{array}$ & Open metal sites & 15 \\
\hline $\begin{array}{c}\text { MFM-300(M) } \\
\left(\mathrm{M}=\mathrm{Al}, \mathrm{V}^{\mathrm{IV}}, \mathrm{Fe}, \mathrm{V}^{\mathrm{III}}, \mathrm{Cr}\right)\end{array}$ & $15.7,17.3,13.4,10.2,6$ & $\begin{array}{c}>40,{ }^{*} \sim 50,{ }^{*} \sim 37,{ }^{*} \\
\sim 40,{ }^{*} \sim 50^{*}\end{array}$ & $\begin{array}{l}\text { bridging } \\
\text { hydroxyl }\end{array}$ & 16 \\
\hline$\left[\mathrm{Ni}_{2}(\mathrm{adc})_{2}(\mathrm{DABCO})\right]$ & 12.1 & 18 & - & 17 \\
\hline SION105-Eu & $5.7(303 \mathrm{~K})$ & $\begin{array}{l}-28.7 \\
-40.9^{b}\end{array}$ & $\begin{array}{l}\text { Lewis acidic } \\
\text { boron center }\end{array}$ & 18 \\
\hline $\begin{array}{c}\mathrm{PFC}-27, \\
\mathrm{PFC}-27 / \mathrm{CF}_{3} \mathrm{SO}_{3}^{-}, \\
\mathrm{PFC}-27 / \mathrm{CH}_{3} \mathrm{COO}^{-},\end{array}$ & $4.7,{ }^{*} 10.4,{ }^{*} 8.5^{*}$ & $7.03,10.16,8.99$ & $\mathrm{NH}_{3}$-Anion & 19 \\
\hline MFM-303(Al) & 9.9 & $61.5^{\mathrm{c}}$ & $\begin{array}{l}\text { bridging } \\
\text { hydroxyl }\end{array}$ & 20 \\
\hline HKUST-1 & 12.10 & $60-50$ & Open metal sites & 21 \\
\hline $\begin{array}{c}\text { M-MOF-74 } \\
(\mathrm{M}=\mathrm{Mg}, \mathrm{Co}, \mathrm{Cu})\end{array}$ & $7.6,{ }^{\mathrm{d}} 6.7,{ }^{\mathrm{d}} 3.4^{\mathrm{d}}$ & $-116,{ }^{\mathrm{b}}-102,{ }^{\mathrm{b}}-76^{\mathrm{b}}$ & Open metal sites & 22 \\
\hline$[\mathrm{SrOOC}]_{17}-\mathrm{COF}$ & 14.30 & 91.2 & $\begin{array}{l}\text { Acid-base } \\
\text { interaction }\end{array}$ & 23 \\
\hline $\begin{array}{l}\mathrm{M}_{2} \mathrm{Cl}_{2} \mathrm{BBTA} \\
(\mathrm{M}=\mathrm{Co}, \mathrm{Ni})\end{array}$ & $17.95,14.68$ & - & Open metal sites & 24 \\
\hline CPM-100b & 12.6 & $-43^{b}$ & $\begin{array}{l}\text { Lewis acidic } \\
\text { boron center }\end{array}$ & 25 \\
\hline MOF-205 & 16.4 & - & $\begin{array}{c}\text { Acid-base } \\
\text { interaction -OH }\end{array}$ & 26 \\
\hline Fe-MIL-101-SO ${ }_{3} \mathrm{H}$ & 17.8 & - & $\begin{array}{l}\text { Brønsted acid } \\
\text { sites }\end{array}$ & 27 \\
\hline NU-1401 & 8.41 & - & $\begin{array}{l}\text { Ligand-acid } \\
\text { sites }\end{array}$ & 28 \\
\hline
\end{tabular}

*Value estimated from experimental data. ${ }^{a}$ Activation energy of the desorption process. ${ }^{b} \mathrm{Heat}$ of adsorption calculated using computational data. ${ }^{\mathrm{c}} \mathrm{Heat}$ adsorption calculated using differential scanning calorimetry. ${ }^{\mathrm{d} B r e a k t h o r o u g h}$ experiments.

\section{S7. Computational studies}

Monte Carlo simulations. The previously reported crystal structure of MFM-300(Sc) was considered 1 and further geometry optimized at the Density Functional Theory (DFT) level keeping the unit cell parameters fixed. These calculations were carried out using the CP2K package ${ }^{29,30}$ with a plane wave cutoff of 500 Ry and convergence criteria on the self-consistent field interactions, maximum displacement and sum of atomic forces of respectively $1 \times 10^{-6} \mathrm{Ry}, 5 \times 10^{-3} \mathrm{Bohr}$ and $1 \times 10^{-3}$ Bohr/Hartree. Atomic orbitals were treated as valence states using a GGA-PBE functional combined with a double- $\zeta$ valence plus polarization (DZVP) basis set ${ }^{31}$ for the Sc atoms and a triple- $\zeta$ basis set with double polarization (TZ2VP) for the $\mathrm{C}, \mathrm{O}$, and $\mathrm{H}$ atoms. ${ }^{32}$ The DFT-D3 correction ${ }^{33}$ was used to take into account long range dispersive interactions. Atomic partial charges were further calculated using the REPEAT scheme, as implemented in the CP2K package. The atom types and their respective charges are shown in Figure S14. 

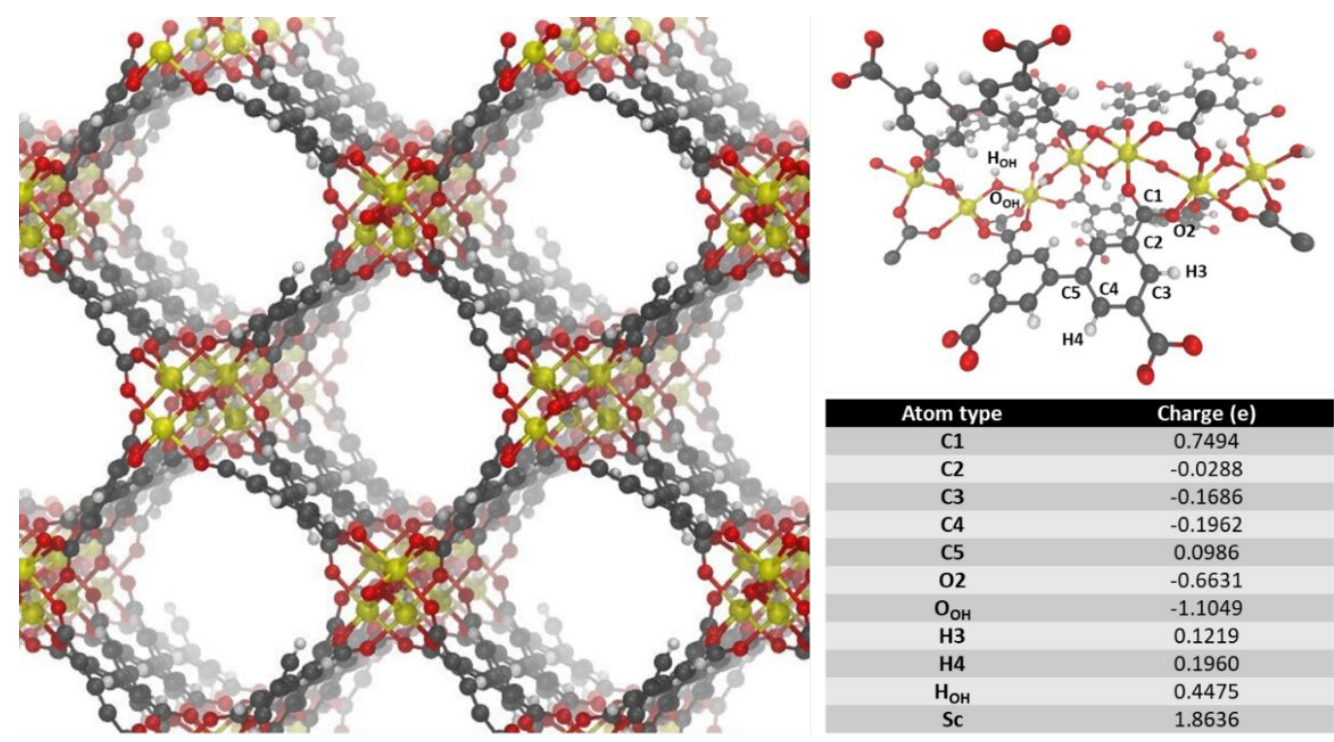

Figure S13. Illustration of the DFT-optimized MFM-300(Sc) structure (left), a zoom of the structure showing its different atom types (upper right) and their corresponding charges (lower right). Sc, C, O and $\mathrm{H}$ atoms are respectively represented in yellow, gray, red and white.

Interatomic interactions were modelled by means of a sum of Lennard-Jones (LJ) and Coulombic potentials. For MFM-300(Sc), the LJ parameters for the atoms of the organic and inorganic moieties were taken from the Dreiding ${ }^{34}$ and UFF ${ }^{35}$ forcefields respectively. $\mathrm{NH}_{3}$ was described by atomistic model previously reported by Eckl et al..$^{36}$ with rigid atom-centered charged LJ sites, a N-H distance of $1.01 \AA$ and a HNH angle of $106^{\circ}$. This atomistic model was previously demonstrated to be accurate for the reproduction of the vapor-liquid equilibrium and critical properties of ammonia. ${ }^{36}$

Grand Canonical Monte Carlo (GCMC) calculations were carried out at $298 \mathrm{~K}$ considering a simulation box made of $8(2 \times 2 \times 2)$ unit cells. For each state point, $2 \times 10^{5}$ Monte Carlo cycles following $1 \times 10^{3}$ equilibration cycles (number of steps $=$ number of cycles $\times$ number of molecules) were used, as implemented in the RASPA software package. ${ }^{37} \mathrm{LJ}$ crossed parameters were calculated using the Lorentz-Berthelot mixture rules. ${ }^{38}$ The resulting van der Waals interactions were considered with a $12 \AA$ cutoff while electrostatic interactions were calculated using the Ewald summation method with a $10^{-6}$ precision. ${ }^{39}$ Adsorption enthalpies were evaluated using the revised Widom's test particle insertion method. ${ }^{40}$ 

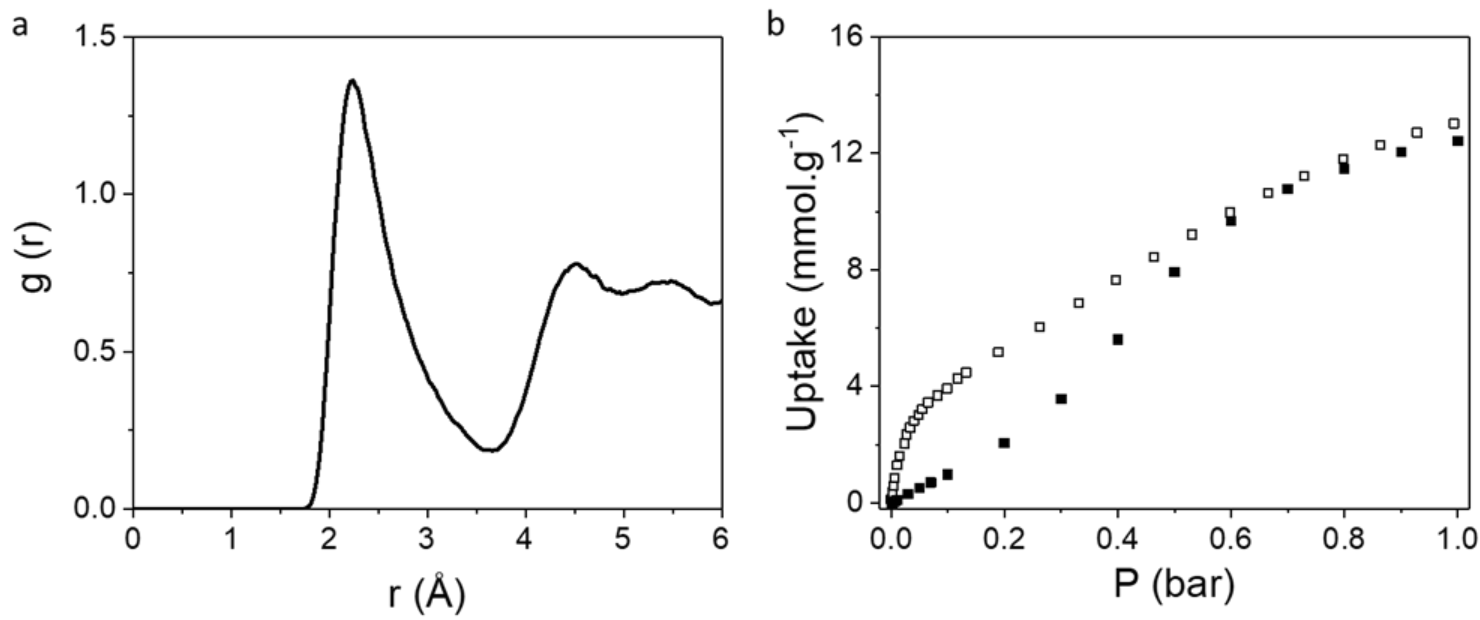

Figure S14. (a) Radial distribution functions obtained at 0.1 bar associated to the $\mathrm{N}_{\mathrm{NH} 3}-\mathrm{H}_{\mu-\mathrm{OH}}$ interacting pairs, (b) Comparison between experimental (open squares) and simulated (closed squares) $\mathrm{NH}_{3}$ adsorption isotherms at $298 \mathrm{~K}$.

Density Functional Theory Calculations. To investigate the adsorption of gas molecules and the reaction of $\mathrm{NH}_{3}$ with MFM-300(Sc), the DFT calculations have been performed using the projected augmented wave $(\mathrm{PAW})^{41}$ formulism within the non-local vdw-DF2 ${ }^{42}$ as implemented in Vienna ab initio simulation package (VASP). ${ }^{43-45}$ The convergence criterion of $0.01 \mathrm{eV} / \AA$ for the force was adapted for geometry optimizations $(0.02 \mathrm{eV} / \AA$ for transition state searching), while the criterion for self-consistent field (SCF) is $10^{-5} \mathrm{eV}$. To figure out possible product of $\mathrm{NH}_{3}$ reacts with MFM-300(Sc), the reaction paths were searched with the climbing image nudged elastic band method (CI-NEB) ${ }^{46}$ as implemented in the Transition State Tools for VASP (VTST) ${ }^{47}$ and verified with frequency calculations. To validate the stability/instability of such product, ab initio molecular dynamics (AIMD) simulations were performed also with VASP but the criterion for self-consistent field (SCF) was increased to $10^{-7} \mathrm{eV}$ with a step size of $0.75 \mathrm{fs}$. All DFT calculations are performed at gamma point, while the cutoff energy of $900 \mathrm{eV}$ for the plane-wave basis set has been consistently used. The lattice parameters optimized for the unit cell of MFM-300(Sc) are $\mathbf{a}=\mathbf{b}=15.47 \AA, \mathbf{c}=12.52 \AA$, $\boldsymbol{\alpha}=\boldsymbol{\beta}=\boldsymbol{\gamma}=90^{\circ}$. 
(a)

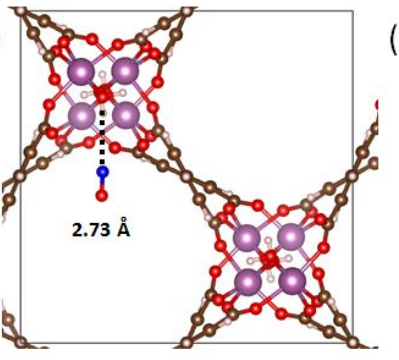

(d)

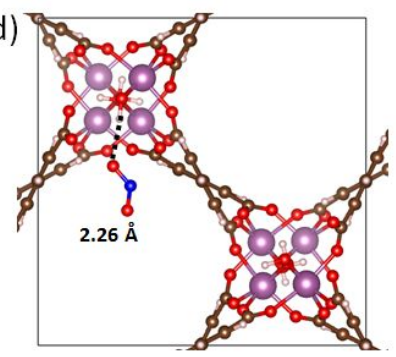

(b)

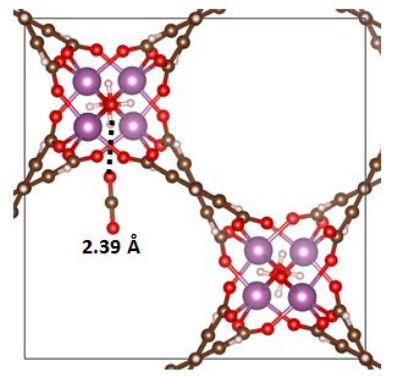

(e)

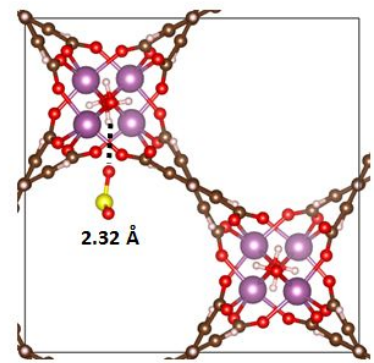

(c)

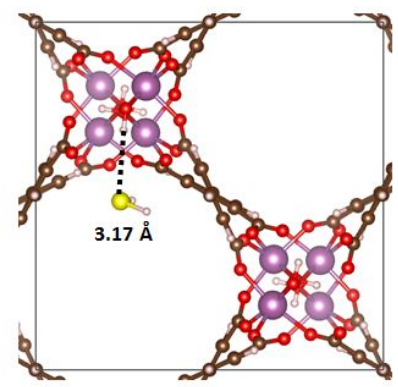

(f)

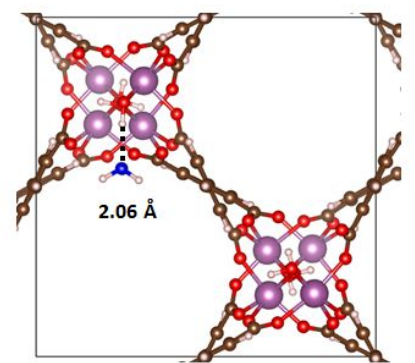

Figure S15: The most stable adsorption configuration of (a) NO, (b) $\mathrm{CO}_{2}$, (c) $\mathrm{H}_{2} \mathrm{~S}$, (d) $\mathrm{NO}_{2}$, (e) $\mathrm{SO}_{2}$ and (f) $\mathrm{NH}_{3}$, within MFM-300(Sc), in the sequence as same as in Table S4. Color code: carbon (brown), oxygen (red), nitrogen (blue), sulfur (yellow), hydrogen (white) and scandium (purple).
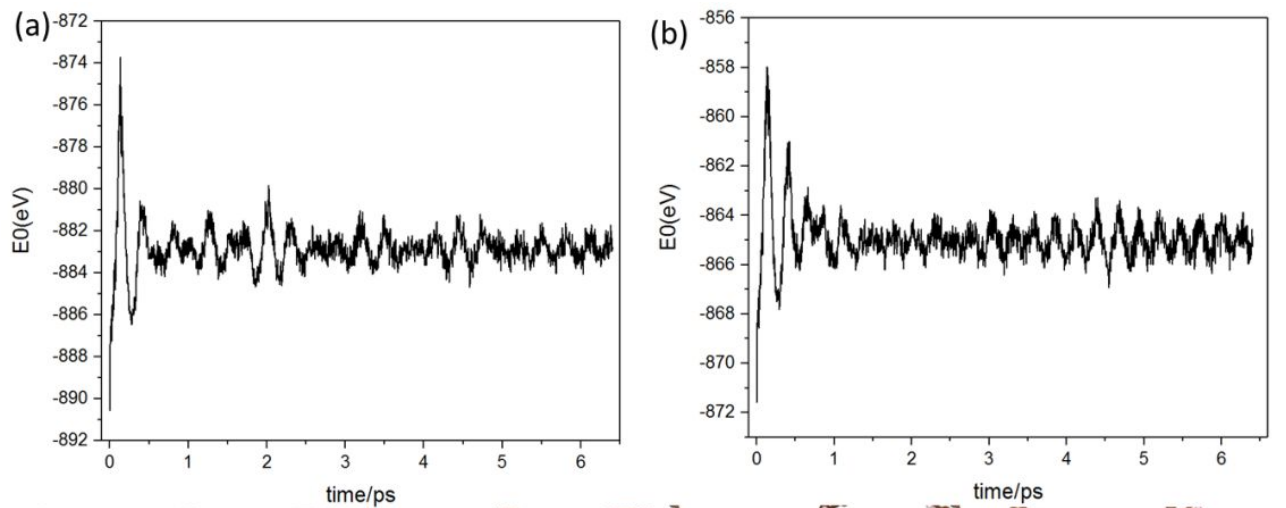

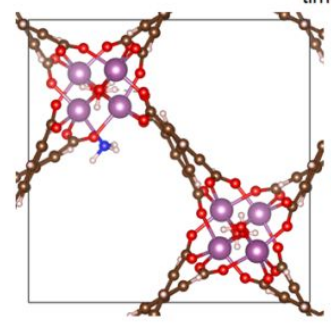

Starting structure

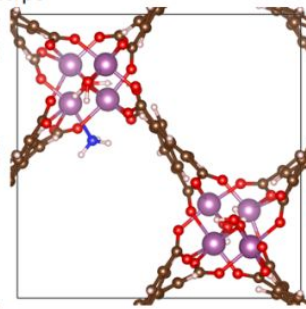

Ending structure

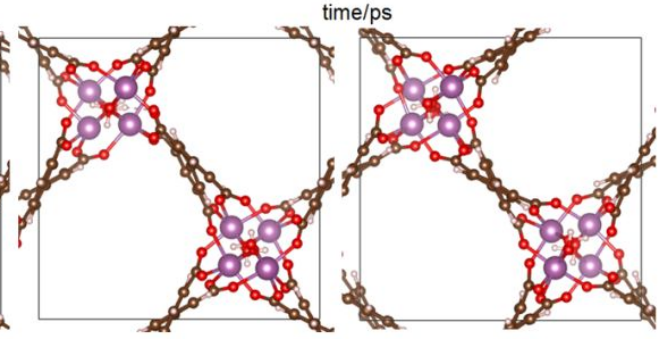

Starting structure

Ending structure

Figure S16: The AIMD potential energy profile starting from (a) FS of Figure 3 and (b) FS of Figure 3 by removing $\mathrm{NH}_{3}$. The ending structures are also shown. Color code: carbon (brown), oxygen (red), nitrogen (blue), sulfur (yellow), hydrogen (white) and scandium (purple).

Table S5: The interaction energy $\left(\Delta E_{\text {int }}\right)$ of guest molecules in MFM-300(Sc); the interaction energy is calculated as $\Delta E_{\text {int }}=E(\mathrm{MOF}+$ guest $)-E(\mathrm{MOF})-E$ (guest), where $E(\mathrm{MOF}+$ guest $), E(\mathrm{MOF})$ and $E$ (guest) are the total energy of MOF with guest, the total energy of MOF and the total energy of 
guest molecule; note both the total energy of MOF and the total energy of guest molecule are calculated with their geometries fixed at corresponding binding mode. The energies are in $\mathrm{kJ} \mathrm{mol}^{-1}$.

\begin{tabular}{cc}
\hline & $\Delta E_{\text {int }}$ \\
\hline MFM-300(Sc) & \\
$\mathrm{NO}$ & -21 \\
$\mathrm{NO}_{2}$ & -28 \\
$\mathrm{CO}_{2}$ & -24 \\
$\mathrm{H}_{2} \mathrm{~S}$ & -26 \\
$\mathrm{SO}_{2}$ & -33 \\
$\mathrm{NH}_{3}(\mu-\mathrm{OH})$ & -40 \\
$\mathrm{NH}_{3}(\mathrm{INT})$ & -51 \\
$\mathrm{NH}_{3}(\mathrm{FS})$ & -65 \\
\hline
\end{tabular}

Table S6: The distances of $\mathrm{Sc}$ and $\mathrm{NH}_{3}(\mathrm{Sc}-\mathrm{N})$ and $\mathrm{Sc}$-carboxylate (Sc-O bond which breaks during reaction), all distances are reported in $\AA$.

\begin{tabular}{lllllll}
\hline & Empty MOF & IS & TS1 & INT & TS2 & FS \\
\hline Sc-N & - & 4.88 & 3.20 & 2.56 & 2.47 & 2.45 \\
Sc-O & 2.12 & 2.14 & 2.17 & 2.22 & 2.76 & 3.70 \\
\hline
\end{tabular}


(a)

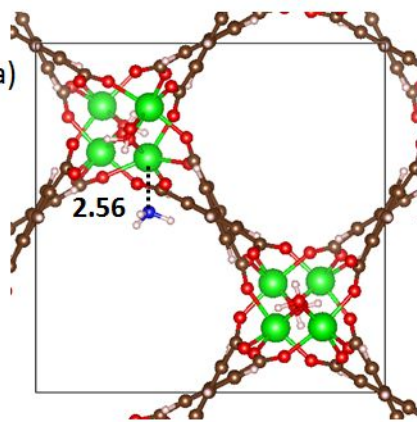

Initial INT for MFM-300(Al)

(geometry from MFM-300(Sc))

Total energy: $-857.59 \mathrm{eV}$

(b)

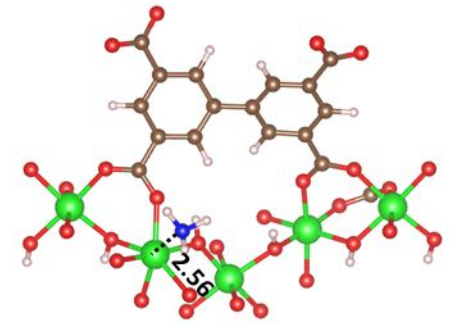

Structure optimization

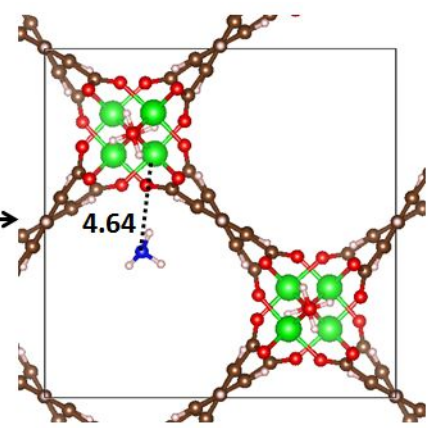

Optimized INT for MFM-300(AI) Total energy: $\mathbf{- 8 6 8 . 6 0 \mathrm { eV }}$

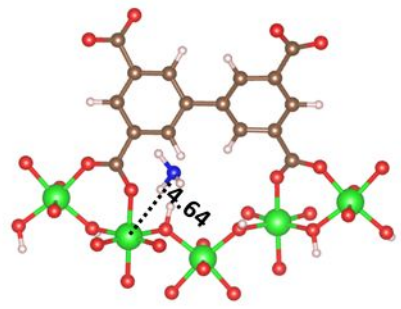

Figure S17: (a) The side views of the initial (left) and the DFT-optimized (right) INT structures for MFM300(Al). (b) The details of the coordination of Al in the initial (left) and the DFT-optimized (right) INT structures. Colour code: carbon (brown), oxygen (red), nitrogen (blue), sulphur (yellow), hydrogen (white) and aluminum (green). The distances are reported in $\AA$.

\section{S8. DRIFT studies}

A

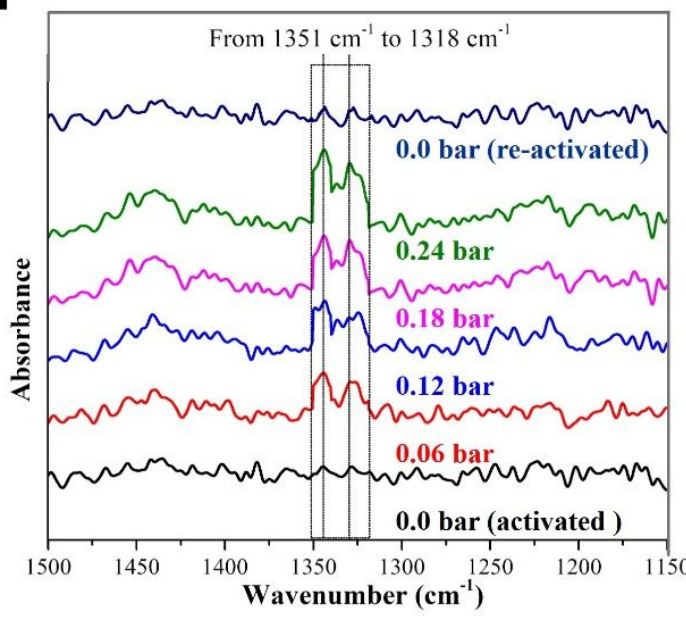

B

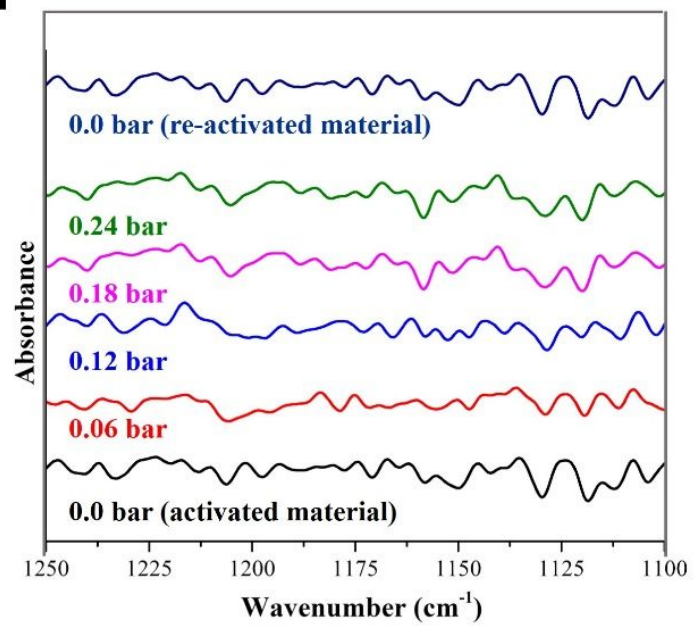

Figure S18. DRIFT spectra of $\mathrm{NH}_{3}$ adsorbed at different pressures (from 0 to 0.24 bar) over activated MFM$300(\mathrm{Sc})$ at $298 \mathrm{~K}$ split in the regions: a) $1500-1150 \mathrm{~cm}^{-1}$, and b) $1250-1100 \mathrm{~cm}^{-1}$. 


\section{References}

[1] G. W. Peterson, G. W. Wagner, A. Balboa, J. Mahle, T. Sewell, C. J. Karwacki, J. Phys. Chem. C 2009, 113, 1390613917.

[2] T. Grant Glover, G. W. Peterson, B. J. Schindler, D. Britt, O. Yaghi, Chem. Eng. Sci. 2011, 66, $163-170$.

[3] M. J. Katz, A. J. Howarth, P. Z. Moghadam, J. B. DeCoste, R. Q. Snurr, J. T. Hupp, O. K. Farha, Dalt. Trans. 2016, $45,4150-4153$.

[4] C. Petit, T. J. Bandosz, Adv. Funct. Mater. 2010, 20, 111-118.

[5] D. Saha, S. Deng, J. Colloid Interface Sci. 2010, 348, 615-620.

[6] A. J. Rieth, Y. Tulchinsky, M. Dincã, J. Am. Chem. Soc. 2016, 138, 9401-9404.

[7] A. J. Rieth, M. Dincã, J. Am. Chem. Soc. 2018, 140, 3461-3466.

[8] S. Moribe, Z. Chen, S. Alayoglu, Z. H. Syed, T. Islamoglu, O. K. Farha, ACS Mater. Lett. 2019, 1, 476-480.

[9] a) T. Kajiwara, M. Higuchi, D. Watanabe, H. Higashimura, T. Yamada, H. Kitagawa, Chem. - A Eur. J. 2014, 20, 15611-15617; b) Y. Chen, F. Zhang, Y. Wang, C. Yang, J. Yang, J. Li, Microporous Mesoporous Mater. 2018, 258, $170-177$.

[10] H. G. W. Godfrey, I. da Silva, L. Briggs, J. H. Carter, C. G. Morris, M. Savage, T. L. Easun, P. Manuel, C. A. Murray, C. C. Tang, M. D. Frogley, G. Cinque, S. Yang, M. Schröder, Angew. Chemie - Int. Ed. 2018, 57, 14778-14781.

[11] I. A. Ibarra, S. Yang, X. Lin, A. J. Blake, P. J. Rizkallah, H. Nowell, D. R. Allan, N. R. Champness, P. Hubberstey, M. Schröder, Chem. Commun. 2011, 47, 8304.

[12] A. Nuhnen, C. A. Janiak, Dalton Trans., 2020, 49, 10295-10307.

[13] H. G. W. Godfrey, I. da Silva, L. Briggs, J. H. Carter, C. G. Morris, M. Savage, T. L. Easun, P. Manuel, C. A. Murray, C. C. Tang, M. D. Frogley, G. Cinque, S. Yang, M. Schröder, Angew. Chemie - Int. Ed. 2018, 57, 14778-14781.

[14] A. J. Rieth, Y. Tulchinsky, M. Dincã, J. Am. Chem. Soc. 2016, 138, 9401-9404.

[15] D. W. Kim, D. W. Kang, M. Kang, J. H. Lee, J. H. Choe, Y. S. Chae, D. S. Choi, H. Yun, C. S. Hong, Angew. Chemie - Int. Ed. 2020, 59, 22531-22536.

[16] X. Han, W. Lu, Y. Chen, I. Da Silva, J. Li, L. Lin, W. Li, A. M. Sheveleva, H. G. W. Godfrey, Z. Lu, F. Tuna, E. J. L. McInnes, Y. Cheng, L. L. Daemen, L. J. M. C. Mcpherson, S. J. Teat, M. D. Frogley, S. Rudić, P. Manuel, A. J. Ramirez-Cuesta, S. Yang, M. Schröder, J. Am. Chem. Soc. 2021, 143, 3153-3161.

[17] F. Cao, Zhejian; Narang, Kritika; Akhtar, Catalysts, 2020, 2, 1-10.

[18] T. N. Nguyen, I. M. Harreschou, J. H. Lee, K. C. Stylianou, D. W. Stephan, Chem. Commun. 2020, 56, $9600-9603$.

[19] M. Khanpour Matikolaei, E. Binaeian, ACS Appl. Mater. Interfaces 2021, 13, 27159-27168.

[20] Marsh, X. Han, J. Li, Z. Lu, S. P. Argent, I. da Silva, Y. Cheng, L. L. Daemen, A. J. Ramirez-Cuesta, S. P. Thompson, A. J. Blake, S. Yang, M. Schröder, J. Am. Chem. Soc. 2021, 143, 6586-6592.

[21] C. Petit, B. Mendoza, T. J. Bandosz, Langmuir 2010, 26, 15302-15309.

[22] M. J. Katz, A. J. Howarth, P. Z. Moghadam, J. B. DeCoste, R. Q. Snurr, J. T. Hupp, O. K. Farha, Dalt. Trans. 2016, $45,4150-4153$.

[23] Y. Yang, M. Faheem, L. Wang, Q. Meng, H. Sha, N. Yang, Y. Yuan, G. Zhu, ACS Cent. Sci. 2018, 4, 748-754.

[24] A. J. Rieth, M. Dinca, J. Am. Chem. Soc. 2018, 140, 3461-3466.

[25] Y. Wang, X. Zhao, H. Yang, X. Bu, Y. Wang, X. Jia, J. Li, P. Feng, Angew. Chemie - Int. Ed. 2019, 58, 6316-6320.

[26] I. Spanopoulos, P. Xydias, C. D. Malliakas, P. N. Trikalitis, Inorg. Chem. 2013, 52, 855-862.

[27] Y. X. Zhou, Y. Z. Chen, Y. Hu, G. Huang, S. H. Yu, H. L. Jiang, Chem. - A Eur. J. 2014, 20, 14976-14980.

[28] Y. Zhang, X. Zhang, Z. Chen, K. ichi Otake, G. W. Peterson, Y. Chen, X. Wang, L. R. Redfern, S. Goswami, P. Li, T. Islamoglu, B. Wang, O. K. Farha, ChemSusChem 2020, 13, 1710-1714.

[29] J. VandeVondele, M. Krack, F. Mohamed, M. PArrinello, T. Chassaing, J. Hutter, Comput. Phys. Commun. 2005, 167, 103-128.

[30] J. Hutter, M. Iannuzi, F. Schiffmann, J. VandeVondele, Wiley Interdiscip. Rev. Comput. Mol. Sci. 2014, 4, $15-25$.

[31] M. Krack, Theor. Chem. Acc. 2005, 114, 145-152.

[32] E. Van Lenthe, E. J. Baerends, J. Comput. Chem. 2003, 24, 1142-1156.

[33] S. GrimmeJ. Antony, S. Ehrlich, H. Krieg, J. Chem. Phys. 2010, 132, 154104.

[34] S. L. Mayo, B. D. Olafson, W. A. Goddard, J. Phys. Chem. 1990, 101, 8897-8909.

[35] A. K. K. Rappé, C. J. J. Casewit, K. S. S. Colwell, W. A Goddard III, W, M. M. Skiff, J. Am. Chem. Soc. 1992, 114, 10024-10035.

[36] B. Eckl, J. Vrabec, H. Hasse, Mol. Phys. 2008, 106, 1039-1046.

[37] D. Dubbeldam, S. Calero, D. E. Ellis, R. Q. Snurr, Mol. Simul. 2016, 42, 81-101.

[38] H. A. Lorentz, Ann. Phys. 1881, 248, 127-136.

[39] P. P. Ewald, Ann. Phys. 1921, 369, 253-287.

[40] T. J. H. Vlugt, E. García-Pérez, D. Dubbeldam, S. Ban, S. Calero, J. Chem. Theory Comput. 2008, 4, $1107-1118$.

[41] J. P. Perdew, K. Burke, M. Ernzerhof, Phys. Rev. Lett. 1997, 78, 1396.

[42] K. Lee, É. D. Murray, L. Kong, B. I. Lundqvist, D. C. Langreth, Phys. Rev. B,2010, 82, 081101.

[43] P. E. Blöchl, Phys. Rev. B, 1994, 50, 17953-17979.

[44] G. Kresse, J. Furthmüller, Phys. Rev. $B$,1996, 54, 11169-11186.

[45] G. Kresse, D. Joubert, Phys. Rev. B, 1999, 59, 1758-1775.

[46] G. Henkelman, B. P. Uberuaga, H. A. Jónsson, J. Chem. Phys. 2000, 113, 9901-9904.

[47] G. Henkelman, Vasp TST tools http://theory.cm.utexas.edu/vtsttools/. 